\title{
Performance in dynamic movement tasks and occurrence of low back pain in youth floorball and basketball players
}

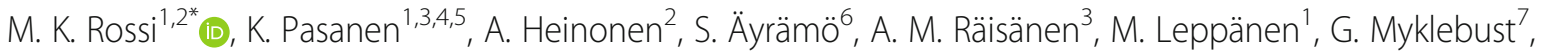
T. Vasankari ${ }^{1}$, P. Kannus ${ }^{1,8}$ and J. Parkkari ${ }^{1,9}$

\begin{abstract}
Background: Prospective studies investigating risk factors for low back pain (LBP) in youth athletes are limited. The aim of this prospective study was to investigate the association between hip-pelvic kinematics and vertical ground reaction force (VGRF) during landing tasks and LBP in youth floorball and basketball players.

Methods: Three-hundred-and-eighty-three Finnish youth female and male floorball and basketball players (mean age $15.7 \pm 1.8$ ) participated and were followed up on for 3 years. At the beginning of every study year the players were tested with a single-leg vertical drop jump (SLVDJ) and a vertical drop jump (VDJ). Hip-pelvic kinematics, measured as femur-pelvic angle (FPA) during SLVDJ landing, and peak VGRF and side-to-side asymmetry of vGRF during VDJ landing were the investigated risk factors. Individual exposure time and LBP resulting in time-loss were recorded during the follow-up. Cox's proportional hazard models with mixed effects and time-varying risk factors were used for analysis.

Results: We found an increase in the risk for LBP in players with decreased FPA during SLVDJ landing. There was a small increase in risk for LBP with a one-degree decrease in right leg FPA during SLVDJ landing (HR 1.09, 95\% Cl 1.02 to 1.17, per one-degree decrease of FPA). Our results showed no significant relationship between risk for LBP and left leg FPA (HR 1.04, 95\% Cl 0.97 to 1.11, per one-degree decrease of FPA), VGRF (HR 1.83, 95\% Cl 0.95 to 3.51 ) or VGRF side-to-side difference (HR 1.22, 95\% Cl 0.65 to 2.27) during landing tasks.

Conclusions: Our results suggest that there is an association between hip-pelvic kinematics and future LBP. However, we did not find an association between LBP and VGRF. In the future, the association between hip-pelvic kinematics and LBP occurrence should be investigated further with cohort and intervention studies to verify the results from this investigation.
\end{abstract}

Level of evidence: Prognosis, level $1 \mathrm{~b}$.

Keywords: Low back pain, Lumbar spine, Team sports, Youth athletes, Risk factors

\footnotetext{
* Correspondence: marleena.k.rossi@student.jyu.fi

${ }^{1}$ Tampere Research Center of Sports Medicine, UKK Institute, 33501 Tampere,

Finland

${ }^{2}$ Faculty of Sport and Health Sciences, University of Jyväskylä, Jyväskylä,

Finland

Full list of author information is available at the end of the article
}

(c) The Author(s). 2020 Open Access This article is licensed under a Creative Commons Attribution 4.0 International License, which permits use, sharing, adaptation, distribution and reproduction in any medium or format, as long as you give appropriate credit to the original author(s) and the source, provide a link to the Creative Commons licence, and indicate if changes were made. The images or other third party material in this article are included in the article's Creative Commons licence, unless indicated otherwise in a credit line to the material. If material is not included in the article's Creative Commons licence and your intended use is not permitted by statutory regulation or exceeds the permitted use, you will need to obtain permission directly from the copyright holder. To view a copy of this licence, visit http://creativecommons.org/licenses/by/4.0/. The Creative Commons Public Domain Dedication waiver (http://creativecommons.org/publicdomain/zero/1.0/) applies to the data made available in this article, unless otherwise stated in a credit line to the data. 


\section{Key points}

Findings Based on the results of this study, peak vGRF is a poor risk factor for LBP in youth team sport players. Hip-pelvic kinematics are associated with increased risk for LBP; smaller angle between the femur and pelvis increases the risk for all LBP and non-traumatic gradual onset LBP.

Implications One cannot discriminate players with future LBP based on the femur-pelvic angle during SLVDJ landing alone. The association between hip-pelvic kinematics and other movement patterns, such as trunk kinematics, and risk for LBP in athletes merits further investigations.

Caution The data recording and statistical analyses in this study did not take into account the temporal nature of physical abilities during the follow-up nor did it include psychosocial factors. Statistical power might not have been enough to reveal small to moderate associations. The results should be verified by future cohort and intervention studies.

\section{Background}

Back pain is common among youth athletes [1]. Our previous findings show that nearly half of floorball players (45\%) and $64 \%$ of basketball players have had LBP during the preceding 12 months [2]. Furthermore, lower extremity injuries (LEI) resulting in time loss are common among these players [3]. Association between LEI and back pain has been suggested by previous research [4-6]. It has been speculated that changes in lower extremity function after an injury, or shared risk factors, might explain the association between LEI and LBP and that plausible mechanisms behind this relationship should be investigated [5]. Sports injury studies have investigated the association between LEI and lower extremity kinetics and kinematics, such as ground reaction forces and lower extremity movement patterns, but they have not considered how these factors might contribute to the cause of LBP.

Previous studies investigating intrinsic risk factors for LBP in youth have focused mostly on lower extremity and trunk muscle strength and endurance, flexibility and anthropometric measures [1, 7]. Prospective investigations into association between LBP and movement patterns in youth athletes are scarce [8] and most of the previous studies investigating back pain in athletes have been largely cross-sectional [9].

It has been stated that the trunk, including lumbo-pelvic-hip complex, is the central point of kinetic chains of most sports activities and essential in decreasing back injuries [10]. Furthermore, it has been suggested that for the functional evaluation of the trunk and lumbo-pelvic-hip complex, dynamic hip-pelvic movement patterns should be investigated [10]. Previous research has identified differences between youth athletes with and without
LBP on lumbo-pelvic-hip complex movement patterns [11-14] and an association between LBP and frontal plane hip-pelvic movement patterns has been observed in single-leg dynamic tasks in youth cricket players [15] and in adults with LBP [16].

Basketball and floorball (an indoor team ball sport that resembles floor hockey) are sports that include running, sudden direction changes and stops. In addition, basketball players perform lots of jumping and landing [17]. These movements produce large ground reaction forces (GRF) $[18,19]$ that transfer to the lumbar spine and thus may pre-dispose players to LBP. Yet, to our knowledge, the association between LBP and peak vGRF nor lumbo-pelvic-hip complex movement patterns, using kinematic measures, have not been investigated in youth floorball and basketball players.

The aim of this exploratory prospective study was to investigate if hip-pelvic kinematics, measured as femurpelvic angle (FPA), and peak vGRF during landing tasks, are associated with LBP incidence in a large cohort of youth basketball and floorball players. The prospective design and consideration of the individual training and game exposure hours adds to the novelty value of this study. The hypotheses were that [1] decreased FPA in frontal plane during single-leg vertical drop jump (SLVDJ) landing and [2] higher or asymmetric peak vGRF during vertical drop jump (VDJ) landing increase the risk for LBP plausibly due to increased load and strain in the lumbo-pelvic area.

\section{Methods}

\section{Study design and data collection}

This study is part of the large Finnish PROFITS study (Predictors of Lower Extremity Injuries in Team Sports) carried out between 2011 and 2015 [20] and the descriptive results regarding LBP have been reported already in previous reports $[1,2]$. This study was approved by the Ethics Committee of the Pirkanmaa Hospital District (ETL-code R10169) and carried out in accordance with the Declaration of Helsinki and the guidelines for good scientific practice. Written informed consent was acquired from the participants (and a legal guardian if the player was under 18 years old).

Ten female and male basketball and 10 floorball teams were recruited from six sports clubs in Tampere, Finland. Players older than 21 and younger than 12 at baseline were excluded. Data were collected at baseline in April or May of 2011, 2012, or 2013 as the player entered the study, and at the beginning of each study year in which the player participated. The players were followed prospectively for up to 3 years. Data from all players entering the follow-up were included in the analyses for the time they participated. 
The baseline questionnaire covered the following demographics: age, sex, dominant leg, nicotine use, family history of musculoskeletal disorders, and training and playing history during the previous 12 months.

The players' history of back pain was recorded using the Standardized Nordic questionnaire of musculoskeletal symptoms (modified version for athletes) [21, 22]. History of previous LBP was determined based on the question: How many days have you had LBP during the past 12 months: 'none' (recorded as no LBP history), ' 1 to 7 days', '8 to 30 days', ' $>30$ days but not daily' and 'daily' (recorded as a history of LBP). The questionnaire has been validated among adults [23]. The baseline questionnaire was completed during the same day as the baseline tests.

The baseline tests were performed at the UKK Institute over 1 day at the beginning of every follow-up year. The test procedures are outlined in more detail in previous reports [20, 24-29] and Table 1 and only briefly described below. Players with an ongoing injury at the time of the baseline test and players who did not have a valid number of test trials were excluded from the risk factor analyses.

The SLVDJ was used to investigate hip-pelvic kinematics. In the SLVDJ the player dropped off from a $10-\mathrm{cm}$ box followed by a maximal vertical jump. Hip-pelvic angles were estimated from a still video image by an investigator using Java-based software (ImageJ, National Institutes of Health), and FPA, outlined in Fig. 1, was chosen for risk factor analysis. The FPA measured in a similar, but not identical 2D single-leg landing task has shown good correlation with 3D measurements [31]. Using the same methods as this study, Stensrud et al. observed moderate to excellent reliability when they measured lower extremity kinematics during the SLVDJ (ICC range $=0.58-0.89$ ) [26]

The VDJ was used to investigate the vGRF during landing. During a valid VDJ test the player stood on the 30-cm box, dropped off the box and immediately after landing the player performed a maximal vertical jump. Absolute and weight adjusted peak vGRF and side-toside asymmetry were investigated as potential risk factors. The same methodology has been used previously by, for example, Nilstad et al., Mok et al. and Krosshaug et al. [27-29]. They also demonstrated good to excellent reliability for peak vGRF measure in athletes (ICC range $=0.60-0.91)[28,29]$.

\section{Injury and sport exposure registration}

The primary outcomes were traumatic and non-traumatic LBP. LBP was defined as pain in the lower back area that prevented the player from taking full part in team practices and games for at least $24 \mathrm{~h}$. LBP that resulted from a specific identifiable event, such as falling, was referred to as acute traumatic LBP. Non-traumatic LBP had gradual onset, without an identifiable event of trauma. Acute traumatic LBP events were categorised as "contact", "indirect
Table 1 Description of selected baseline tests and the investigated variables

\section{SINGLE-LEG VERTICAL DROP JUMP (SLVDJ)}

Preparation Small pieces of sports tape were placed on the left and right side of the upper anterior iliac tubercle (ASIS) and tuberositas tibiae.

Equipment A high-definition digital camera (Sony ${ }^{\circledR}$ Digital HD Video Camera Recorder HXR-NX70E, Sony Corporation, Tokyo, JAPAN).

Warm up No separate warm-up was performed, as the SLVDJ immediately followed a previous test (not included in this study). One practice trial on each leg was allowed.

Test performance During the test the player stood in front of the video camera, on a 10-cm box. Using one leg, the player dropped off the box and landed on one leg. Immediately after landing, the player performed a maximal jump straight up with the same leg. (The test was performed three times.) An overhead goal was used for maximum effort [30] and the test started with the right leg. Trials with jumping, a leg touching the ground or falling/clear loss of balance, were considered invalid. Two valid trials was considered acceptable.

Measurements/Calculations The frontal plane knee and pelvic angles were estimated by a physiotherapist by marking the knee joint centre and ASIS in the still image captured from a video. Joint angles were estimated at the point of maximum knee flexion during initial landing. Femur-pelvic angle (FPA) described the angle between the femur and pelvis and was calculated from the intersection of a line created by ASIS and the knee joint centre. A smaller angle indicates increased femur adduction and/or pelvic drop.

\section{VERTICAL DROP JUMP (VDJ):}

Preparation A static calibration trial was performed.

Equipment The 3D motion analysis consisted of eight cameras (Vicon T40, Oxford, UK), 16 lower body markers (Plug-In Gait, Vicon, Oxford, UK) and two force plates (AMTI, Watertown, Massachusetts) where data were recorded synchronously at $300 \mathrm{fps}$ and $1500 \mathrm{~Hz}$. A 30-cm box was used.

Warm up Players performed a standardised warm-up ( 5 min of cycling) before testing. One practice trial was allowed.

Test performance The player stood on the 30-cm box, dropped off the box and landed symmetrically on both feet on the force plates. Immediately after landing the player jumped as high as possible. An overhead goal was used for maximum effort [30] and the player tried to touch the goal with their head. Three valid trials were collected. The trials were accepted if the entire foot landed on the force plate and the markers stayed tightly on the athlete's skin throughout the task.

Measurements/Calculations Vicon Nexus Plug-in Gait model was used for the analyses. Peak vGRF and vGRF asymmetry were investigated as potential risk factors. Three trials from both legs were averaged and the side with the larger value was chosen for analyses as peak vGRF. Peak vGRF was normalized by bodyweight. The vGRF asymmetry was calculated as the difference between the right and left legs. GRF was filtered using a fourth-order Butterworth filter with cutoff frequencies of $15 \mathrm{~Hz}$ and the landing phase was defined as the period when the unfiltered ground reaction force exceeded $20 \mathrm{~N}$.

contact", and "non-contact" [32]. A contact injury was defined as an injury sustained by the injured body region because of direct contact with another player or object and were excluded from this investigation. An indirect contact and non-contact injury were defined as occurring without direct contact to the injured body region.

Once a week one of the two study physicians contacted the teams to interview the injured players. A structured injury questionnaire (Supplementary Table 1) 


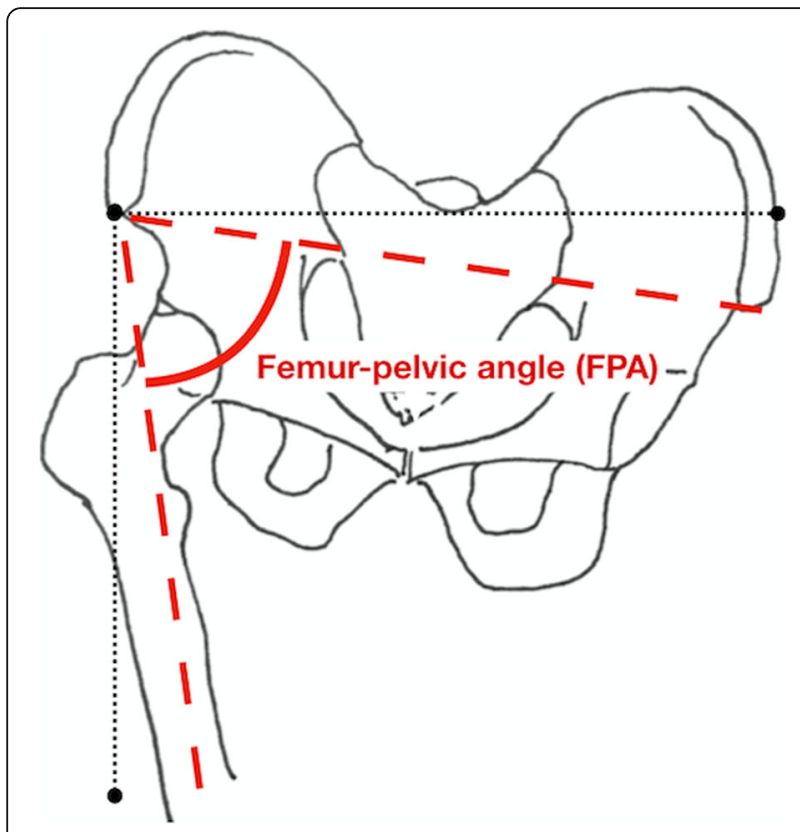

Fig. 1 Femur-pelvic angle (FPA) measured from the still-video image in single-leg vertical drop jump (SLVDJ) test

was used to register the injury/pain location, cause, type, time of onset and the suspected mechanism (acute traumatic vs. non-traumatic gradual onset) based on recommendations of Fuller et al. [33]. During the follow-up, the coaches collected all hours in games and team practices for each player on a monthly basis. Individual practice performed outside the scheduled team events was not included in the exposure data.

\section{Statistical methods}

IBM SPSS Statistics (v. 23-24.0) and Chi-square test and the t-test (Mann-Whitney test when appropriate) were used for descriptive statistical analyses and the results were reported as the mean and standard deviation (SD). Cox's proportional hazard models with mixed-effects were used to investigate the associations between potential risk factors and LBP (yes/no). This method accounts for the sports exposure and variance in follow-up time between the players. Mixed effects were used to account for the sports club as a random effect. Time-dependent variables were used, when possible, due to the tendency of changes in investigated variables over time. The individual game and practice hours from the start of the follow-up until the first event (LBP) or the end of follow-up (if no event) were included in analyses. For players reporting more than one LBP after the baseline, only the first was included. Data from all eligible players entering the follow-up were included in the analyses for the time they participated.

R (v 3.1.2; R Foundation for Statistical Computing [34]) package coxme [35] was used for the risk factor analyses. Univariate analyses were followed by multivariable analyses, where the number of adjusting variables was dependent on the number of events (10 per variable) included in the analysis, as recommended by Peduzzi et al. [36, 37]. The adjusting variables were selected from the following factors: age, sex, BMI, nicotine use, leg dominance, family history of LBP, and history of LBP. Leg dominance was used as a two-category variable: the categories 'left' and 'right' were merged into 'unilateral leg dominance' and the category 'don't know/both' into 'bi-lateral/unknown leg dominance'. The adjusting factors were selected by dropping factors from the model one by one, based on their statistical significance. Only nicotine use, a history of LBP and leg dominance showed a statistically significant association with LBP. The analyses were performed using continuous and dichotomized variables. Variables were dichotomized into 'high' and 'low' using the median. The results are presented as hazard ratios (HR), 95\% CIs and p-values. The player was considered as the unit of analysis, but in unilateral tasks the right and left sides were investigated separately.

\section{Results}

Nine teams of both sports agreed to participate (Fig. 2), with a mean follow-up time of 16.5 months (range 1 to 36 months). Player demographics and baseline test results from each study year are presented in Table 2 . There were some differences between the players included and excluded from the tests (Supplementary Table 2). For example, more male players and heavier players were excluded from the SLVDJ test due to ongoing injuries and for not having a valid test result. The players excluded from the VDJ test were older and heavier than those that were included.

During the follow-up, altogether 566 athlete-years were recorded. Fifty-four percent of players $(n=205)$ reported no history of LBP at baseline. Of the 383 players, $13 \%(n=48)$ sustained LBP during the follow up, $35 \%$ of them $(n=17)$ had not had back pain prior to the study. Half of the players developing LBP during the follow-up

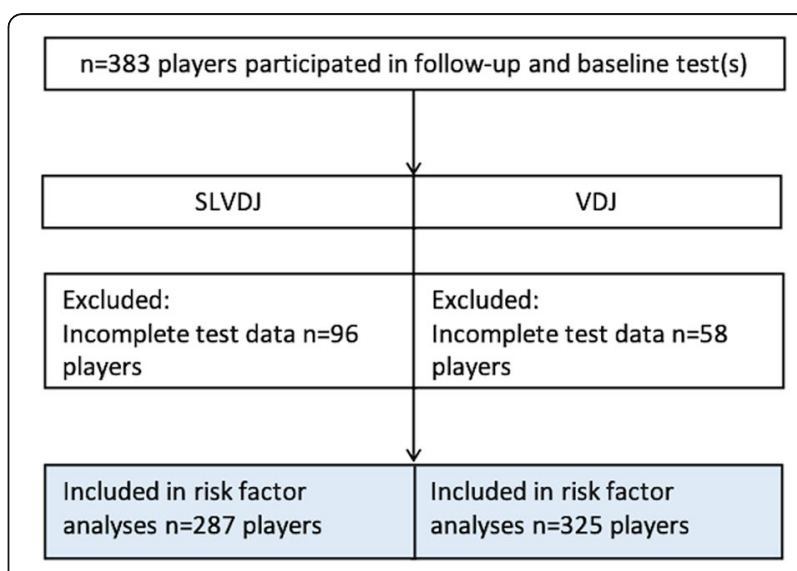

Fig. 2 Study participant flow 
Table 2 Baseline characteristics, baseline test results, and practice and game exposure during the follow up for players with and without LBP

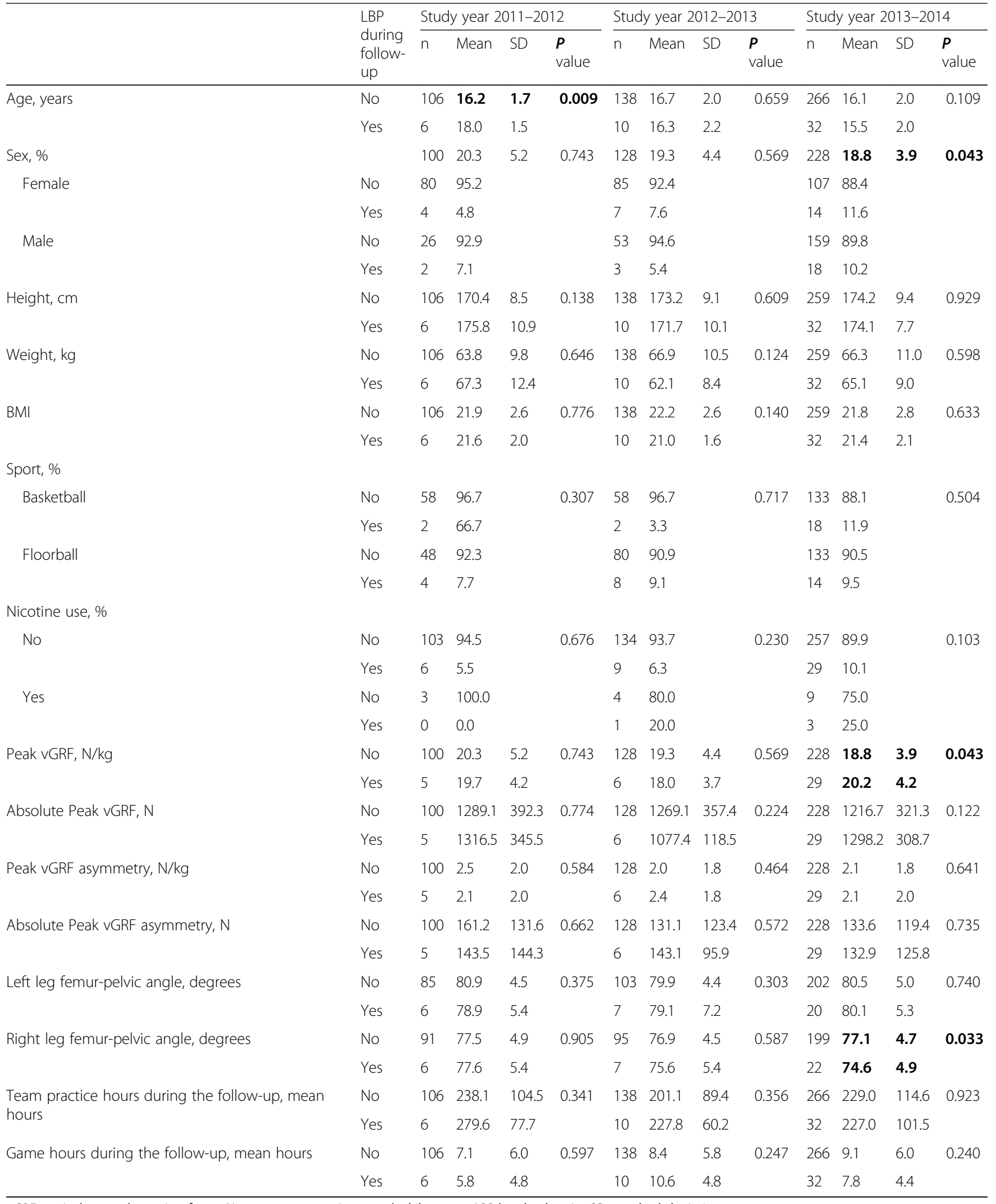


were females $(52 \%, n=25)$. Fifty-four percent of floorball players and $46 \%$ of basketball players had LBP during the follow-up. Most of the players who developed back pain during the follow up did so during their first follow-up year (81\%) and only one player was followed for 3 years before developing LBP. LBP incidence was addressed in a previous publication [1].

\section{Risk factor analyses}

Our results showed that the players who had a smaller FPA during SLVDJ when landing on their right leg were at increased risk for all LBP and for gradual onset non-traumatic LBP (Table 3 ). The analysis using dichotomous risk factors showed that players with $80^{\circ} \mathrm{FPA}$ or less during right leg landing, had 2.2 times higher risk for LBP during the followup, than players with more than $80^{\circ} \mathrm{FPA}$. There was no statistically significant association between risk for LBP and FPA during left leg landing from the SLVDJ.

In the third study year, mean peak vGRF was significantly higher in players who developed LBP during the follow-up (20.2 vs. $18.8 \mathrm{~N} / \mathrm{kg}$, p-value 0.033$)$, but no significant differences were observed between previous study years (Table 2). The Cox risk factor analyses showed no association between peak vGRF measures and LBP incidence in young floorball and basketball players (Table 4).

\section{Discussion}

The aim of this study was to investigate whether hippelvic kinematics and peak vGRF during landing tasks were associated with LBP incidence in youth floorball and basketball players. The first hypothesis was that the movement pattern, where the FPA is decreased during SLVDJ landing due to increased movement of the hip in the direction of adduction and contralateral pelvis drop might predispose for LBP. The second hypothesis was that players with higher or asymmetric peak vGRF during VDJ landing are at increased risk for LBP. Contrary to our second hypothesis, we did not find a statistically significant association between LBP and peak vGRF. However, our results suggested that there is an association between hip-pelvic kinematics and LBP.

The lumbo-pelvic function is an essential part of successful athletic performance [10]. According to a conceptual framework of the kinetic chain [38], a decreased or increased movement somewhere in the kinetic chain is compensated for elsewhere along the chain. This has also been suggested by Garci et al. (2015), who observed that a change in frontal plane knee kinematics resulted in changes higher in the kinetic chain [39]. It has also been shown that stability in inferior segments, such as the lower leg, is significantly correlated with superior segments, such as pelvis and back, and therefore trunk stability may be dependent on the stability of lower segments [40]. Thus, based on the kinetic chain theory it

Table 3 Cox regression analysis results for femur-pelvic angle (FPA) during single-leg vertical drop jump

\begin{tabular}{|c|c|c|c|c|c|c|}
\hline \multirow[t]{2}{*}{ Continuous variables ${ }^{\mathbf{b}, \mathbf{c}}$} & \multicolumn{3}{|c|}{ Univariate } & \multicolumn{3}{|c|}{ Adjusted } \\
\hline & $\mathrm{HR}$ & $95 \% \mathrm{Cl}$ & $\boldsymbol{P}$ value & $\mathrm{HR}$ & $95 \% \mathrm{Cl}$ & $\boldsymbol{P}$ value \\
\hline \multicolumn{7}{|l|}{ All LBP } \\
\hline Femur-pelvic angle, left side $\left({ }^{\mathrm{a}}\right)$ & 1.04 & (0.97 to 1.11$)$ & 0.240 & 1.04 & (0.97 to 1.11$)$ & 0.310 \\
\hline Femur-pelvic angle, right side $\left(^{\mathrm{a}}\right)$ & 1.09 & (1.02 to 1.17$)$ & 0.011 & 1.09 & (1.02 to 1.17$)$ & 0.014 \\
\hline \multicolumn{7}{|l|}{ Gradual onset non-traumatic LBP } \\
\hline Femur-pelvic angle, left side $\left(^{\mathrm{a}}\right)$ & 1.04 & (0.96 to 1.11$)$ & 0.370 & 1.03 & (0.95 to 1.11$)$ & 0.480 \\
\hline Femur-pelvic angle, right side $\left({ }^{\mathrm{a}}\right)$ & 1.10 & (1.02 to 1.18$)$ & 0.013 & 1.09 & (1.01 to 1.18 ) & 0.021 \\
\hline \multicolumn{7}{|l|}{ Dichotomous variables ${ }^{d}$} \\
\hline \multicolumn{7}{|l|}{ All LBP } \\
\hline Femur-pelvic angle, left side (low vs high) & 1.80 & (0.91 to 3.57$)$ & 0.094 & 1.86 & (0.94 to 3.71$)$ & 0.076 \\
\hline Femur-pelvic angle, right side (low vs high) & 2.15 & (1.10 to 4.21$)$ & 0.026 & 2.19 & (1.12 to 4.30$)$ & 0.023 \\
\hline \multicolumn{7}{|l|}{ Gradual onset non-traumatic LBP } \\
\hline Femur-pelvic angle, left side (low vs high) & 1.72 & (0.79 to 3.73$)$ & 0.170 & 1.80 & (0.83 to 3.90$)$ & 0.140 \\
\hline Femur-pelvic angle, right side (low vs high) & 2.25 & (1.07 to 4.72$)$ & 0.033 & 2.30 & (1.09 to 4.84$)$ & 0.028 \\
\hline
\end{tabular}

$H R$ Hazard ratio, $\mathrm{Cl}$ confidence interval, all LBP acute traumatic and gradual non-traumatic low back pain

a degrees

${ }^{\mathrm{b}}$ Adjusted with history of LBP, leg dominance

${ }^{c}$ HR calculated per one-degree decrease

${ }^{\mathrm{d}}$ Adjusted with history of LBP

Femur-pelvic angle, left side high $>=80.0^{\circ}$, low $<80.0^{\circ}$

Femur-pelvic angle, right side high $>=76.3^{\circ}$, low $<76.3^{\circ}$

Statistically significant results are indicated with bold 
Table 4 Association between peak vGRF measures and injury risk for all LBP and gradual onset non-traumatic LBP

\begin{tabular}{|c|c|c|c|c|}
\hline & \multicolumn{2}{|l|}{ Univariate } & \multicolumn{2}{|l|}{ Adjusted } \\
\hline & $\mathrm{HR} 95 \% \mathrm{Cl}$ & $\boldsymbol{P}$ value & $\mathrm{HR95 \%} \mathrm{Cl}$ & $\boldsymbol{P}$ value \\
\hline \multicolumn{5}{|l|}{ Continuous variables $^{a}$} \\
\hline \multicolumn{5}{|l|}{ All LBP } \\
\hline Peak vGRF, N/Kg & $1.03(0.97$ to 1.11$)$ & 0.340 & $1.03(0.96$ to 1.11$)$ & 0.380 \\
\hline Absolute Peak vGRF, N & $1.00(1.00$ to 1.00$)$ & 0.760 & $1.00(1.00$ to 1.00$)$ & 0.870 \\
\hline Peak vGRF asymmetry, N/Kg & $1.00(0.85$ to 1.18$)$ & 0.990 & $1.00(0.85$ to 1.18$)$ & 0.990 \\
\hline Absolute Peak vGRF asymmetry, N & $1.00(1.00$ to 1.00$)$ & 0.970 & $1.00(1.00$ to 1.00$)$ & 0.940 \\
\hline \multicolumn{5}{|l|}{ Gradual onset non-traumatic LBP } \\
\hline Peak vGRF, N/Kg & $1.00(1.00$ to 1.00$)$ & 0.610 & $1.00(1.00$ to 1.00$)$ & 0.690 \\
\hline Absolute Peak vGRF, N & $1.04(0.96$ to 1.12$)$ & 0.370 & $1.03(0.96$ to 1.12$)$ & 0.420 \\
\hline Peak vGRF asymmetry, N/Kg & $1.03(0.87$ to 1.23$)$ & 0.720 & $1.02(0.86$ to 1.22$)$ & 0.810 \\
\hline Absolute Peak vGRF asymmetry, N & $1.00(1.00$ to 1.00$)$ & 0.710 & $1.00(1.00$ to 1.00$)$ & 0.790 \\
\hline \multicolumn{5}{|l|}{ Dichotomous variables ${ }^{\mathrm{b}}$ (high vs. low) } \\
\hline \multicolumn{5}{|l|}{ All LBP } \\
\hline Peak vGRF, N/Kg & $1.92(1.00$ to 3.68$)$ & 0.051 & $1.83(0.95$ to 3.51$)$ & 0.070 \\
\hline Absolute Peak vGRF, N & 0.99 (0.53 to 1.83$)$ & 0.960 & $0.94(0.51$ to 1.76$)$ & 0.860 \\
\hline Peak vGRF asymmetry, N/Kg & 1.23 (0.66 to 2.30$)$ & 0.510 & $1.22(0.65$ to 2.27$)$ & 0.530 \\
\hline Absolute Peak vGRF asymmetry, N & $1.21(0.65$ to 2.25$)$ & 0.550 & $1.20(0.64$ to 2.23$)$ & 0.580 \\
\hline \multicolumn{5}{|l|}{ Gradual onset non-traumatic LBP } \\
\hline Peak vGRF, N/Kg & $1.47(0.73$ to 2.98$)$ & 0.610 & $1.41(0.69$ to 2.86$)$ & 0.340 \\
\hline Absolute Peak vGRF, N & 0.98 (0.49 to 1.97$)$ & 0.370 & 0.94 (0.47 to 1.88$)$ & 0.850 \\
\hline Peak vGRF asymmetry, N/Kg & $1.31(0.65$ to 2.64$)$ & 0.720 & $1.30(0.64$ to 2.61$)$ & 0.470 \\
\hline Absolute Peak vGRF asymmetry, N & $1.28(0.64$ to 2.58$)$ & 0.710 & $1.26(0.63$ to 2.54$)$ & 0.510 \\
\hline
\end{tabular}

$H R$ Hazard ratio, $C l$ confidence interval, $L B P$ low back pain, $V G R F$ vertical ground reaction force, $N$ Newton;

${ }^{a}$ Adjusted with history of LBP, leg dominance and nicotine use

${ }^{b}$ All LBP: Adjusted with history of LBP and leg dominance. Gradual onset LBP: Adjusted with history of LBP

Peak vGRF high $>=18.5$, low $<18.5$

Absolute Peak vGRF high $>=1191.0$, low $<1191.0$

Peak vGRF asymmetry high $>=1.6$, low $<1.6$

Absolute Peak vGRF asymmetry high $>=103.3$, low $<103.3$

Statistically significant results are indicated with bold

could be hypothesised that the decreased FPA may result in movement compensations and increased load and strain up and down the kinetic chain, that is in the lumbo-pelvic area as well as in the knee and lower leg. The association of trunk, pelvis and hip kinematics in relation to lower extremity complaints has been discussed [41] and previous research suggests that dysfunction distal to the injury site can be associated with future injury occurrence $[42,43]$.

Our results showed a small increase in risk (8\%) for LBP with a one-degree decrease in the right leg FPA during the SLVDJ landing. This means a 2.2-fold increase in risk in players with less than $80^{\circ} \mathrm{FPA}$ during the right leg landing, compared to the players with more than $80^{\circ}$ FPA. However, no association was detected between the left leg FPA and the risk of LBP. The difference between the right and left leg results might be due to the test procedure where the starting leg was not randomized, that is, the test was always started with the right leg. Another explanation may be the fact that in most players the right leg was their dominant (kicking) leg and the left leg was their supporting leg. This may explain why the left side was more stable during the SLVDJ. Our results are in line with previous studies suggesting that hip-pelvic kinematics are associated with injuries in athletes [11, 44, 45]. For example, findings from Bayne et al. indicated that increased knee valgus and hip adduction movements might result in increased repetitive compensatory movements from the pelvis and trunk [45]. Frontal hip-pelvic kinematics have been linked with trunk kinematics, for example increased trunk lateral lean, during single-leg tasks [46]. Gluteal muscle dysfunction has been associated with LBP [47], and it could be speculated that gluteal muscle dysfunction could result in inability to control the movement of the hip-pelvic complex during single-leg landing. In addition, the hip-pelvic movement pattern observed in this study 
might also be a compensatory movement resulting from several other factors, such as decreased control of the trunk over the pelvis or even control of the ankle. Therefore, in future studies, it is important to study the kinematics of the entire kinetic chain and not just a part of it.

Our second hypothesis was that vGRFs that affect the lumbar spine [19] could potentially predispose for back pain. However, to our knowledge the association between peak vGRF and LBP incidence in youth athletes has not been studied previously. According to our findings, there was no association between LBP incidence and peak vGRF or vGRF side-to-side asymmetry, measured in VDJ landing. In a cross-sectional investigation, Müller et al. were also unable to find a difference in vGRFs of youth athletes with and without LBP [48]. Future studies should investigate if loading rate is associated with LBP, because it has been shown to be a stronger risk factor for lower extremity injuries than peak GRF [49].

\section{Methodological considerations}

The strengths of this study were the prospective design and the methods of LBP and playing exposure registrations. In addition, the sample size was relatively large. The length of follow-up varied across the sample and therefore we used Cox regression analysis. Cox regression analysis can adjust for variations in the amount of sport participation (follow-up time). Yet, due to the relatively low number of LBP events, we were unable to stratify the analyses by sex. However, it seemed that sex was not significantly associated with LBP in this sample.

Risk factors can change over time and therefore we used time-varying variables in the Cox analysis, when possible. In addition, over half (54.5\%) of the players had a history of LBP at the beginning of the study and 35\% ( $n=17$ ) of the LBP recorded during follow-up was firsttime LBP. We compensated for this by adjusting the risk factor analyses with a history of LBP.

We should not overlook the fact that up to $25 \%$ of all players participating $(n=383)$ were not included in the risk factor analyses. In the SLVDJ $25 \%$ of the players and in the VDJ 19\% of the players had incomplete baseline test data. The absence of these players might affect the results of this study. We are also unaware whether players refusing to participate differ from our sample. Another limitation is that we did not test the reliability of the selected tests during this study. However, the reliability of vGRF measurements has been demonstrated previously by Krosshaug and Mok and their colleagues $[28,29]$. Herrington and others demonstrated in a similar test that frontal plane FPA is a reliable measurement [31]. One limitation is that in the SLVDJ test the starting leg was not randomized. The players performed the test first with the right leg and this might have had an effect on the results. When performing the test with the left leg, the players were more experienced.

The aetiology of LBP has been shown to be multifactorial [50], meaning that, in addition to external loading, internal loading such as psychosocial stress should also be recorded. The latter has been associated with the risk of sports injuries in general [51]. There are also several other risk factors that should be taken into account, such as trunk muscle symmetry [52], in addition to acknowledging the fact that risk factors are dynamic in nature and change over time [53].

\section{Conclusions}

Our results suggested that there is an association between hip-pelvic kinematics and LBP, as measured in this study. However, we did not find a statistically significant association between LBP peak vGRF or side-toside asymmetry of vGRF during VDJ landing. In the future, the association between hip-pelvic kinematics and LBP incidence should be investigated further to verify the results from this study.

\section{Supplementary information}

Supplementary information accompanies this paper at https://doi.org/10. 1186/s12891-020-03376-1.

Additional file 1 Supplementary Table 1. Data collected in the structured injury questionnaire.

Additional file $\mathbf{2}$ Supplementary Table $\mathbf{2}$. Differences between players with and without baseline test result.

\section{Abbreviations}

LBP: Low back pain; Cl: Confidence interval; SLVDJ: Single-leg vertical drop jump; VDJ: Vertical drop jump; HR: Hazards ratio; FPA: Femur-pelvic angle; VGRF: Vertical ground reaction force; GRFs: Ground reaction forces; 2D: Twodimensional; 3D: Three-dimensional; SD: Standard deviation; N: Newton; Kg: Kilograms

\section{Acknowledgements}

We are grateful to statistician Kari Tokola for his indispensable support with the statistical methods. We are also thankful to study physicians Jussi Hietamo and Teemu Ekola for injury data collection, and research assistant Irja Lahtinen for the collection of training and match data and keeping contact with the participating teams.

\section{Financial disclosure and conflict of interest}

The authors affirm that we have no financial affiliation (including research funding) or involvement with any commercial organization that has a direct financial interest in any matter included in this manuscript, except as disclosed in an attachment and cited in the manuscript. Any other conflict of interest (i.e., personal associations or involvement as a director, officer, or expert witness) is also disclosed in an attachment.

\section{Authors' contributions}

All authors contributed to the study concept and design. KP was responsible for conducting the data acquisition. AMR was responsible for preparation of $2 \mathrm{D}$ video analysis data. $\mathrm{ML}$ was responsible for preparation of the $3 \mathrm{D}$ motion capture data. MR was responsible for the main data analysis, interpretation and writing the first draft of the manuscript. KP, AH, SÄ, AMR, ML, GM, TV, PK, and JP were significant manuscript revisers. All authors have approved the submitted version of the manuscript. KP is the guarantor. 


\section{Authors' information}

Not applicable.

\section{Funding}

The PROFITS study was financially supported by the Finnish Ministry of Education and Culture, and the Competitive State Research Financing of the Expert Responsibility Area of Tampere University Hospital (Grants 9 N053, 9S047, 9 T046, 9 U044). The corresponding author was supported with research grants from the University of Jyväskylä and City of Kangasala (Björqkvist's fund)

\section{Availability of data and materials}

An anonymized form of the data can be made available from the corresponding author upon reasonable request.

\section{Ethics approval and consent to participate}

The Ethics Committee of Pirkanmaa Hospital District (ETL-code R10169). The study was carried out in accordance with the Declaration of Helsinki and the guidelines for good scientific practice. Written informed consent was acquired from the participants (and a legal guardian if the player was under 18 years old).

\section{Consent for publication}

Not applicable.

\section{Competing interests}

None declared.

\section{Author details}

${ }^{1}$ Tampere Research Center of Sports Medicine, UKK Institute, 33501 Tampere, Finland. ${ }^{2}$ Faculty of Sport and Health Sciences, University of Jyväskylä, Jyväskylä, Finland. ${ }^{3}$ Sport Injury Prevention Research Centre, Faculty of Kinesiology, University of Calgary, Calgary, Canada. ${ }^{4}$ Alberta Children's Hospital Research Institute, University of Calgary, Calgary, Canada. ${ }^{5}$ McCaig Institute for Bone and Joint Health, University of Calgary, Calgary, Canada. ${ }^{6}$ Faculty of Information Technology, University of Jyväskylä, Jyväskylä, Finland. 'Oslo Sports Trauma Research Center, Department of Sports Sciences, Norwegian School of Sport Sciences, Oslo, Norway. ${ }^{8}$ Department of Orthopedics \& Traumatology, Tampere University Hospital, Tampere, Finland. ${ }^{9}$ Tampere University Hospital, Tampere, Finland.

Received: 16 December 2019 Accepted: 28 May 2020

Published online: 05 June 2020

\section{References}

1. Rossi MK, Pasanen K, Heinonen A, Myklebust G, Kannus P, Kujala UM, et al. Incidence and risk factors for back pain in young floorball and basketball players: a prospective study. Scand J Med Sci Sports. 2018;28(11):2407-15. https://doi.org/10.1111/sms.13237.

2. Pasanen K, Rossi M, Parkkari J, Kannus P, Heinonen A, Tokola K, et al. Low back pain in young basketball and floorball players. Clin J Sport Med. 2016; 26(5):376-80. https://doi.org/10.1097/JSM.0000000000000263.

3. Leppänen M, Pasanen K, Kujala UM, Parkkari J. Overuse injuries in youth basketball and floorball. Open Access J Sports Med. 2015;6:173-9. https:// doi.org/10.2147/OAJSM.S82305

4. Zazulak BT, Hewett TE, Reeves NP, Goldberg B, Cholewicki J. Deficits in neuromuscular control of the trunk predict knee injury risk. Am J Sports Med. 2007:35(7):1123-30. https://doi.org/10.1177/0363546507301585.

5. Seay J, Shing T, Wilburn K, Westrick R, Kardouni J. Lower-extremity injury increases risk of first-time low back pain in the US army. Med Sci Sports Exerc. 2018;50(5):987-94. https://doi.org/10.1249/MSS.0000000000001523.

6. Fuglkjær S, Vach W, Hartvigsen J, Wedderkopp N, Junge T, Hestbæk L. Does lower extremity pain precede spinal pain? A longitudinal study. Eur J Pediatr. 2018;177(12):1803-10. https://doi.org/10.1007/s00431-018-3235-6.

7. Potthoff $T$, de Bruin ED, Rosser S, Humphreys BK, Wirth B. A systematic review on quantifiable physical risk factors for non-specific adolescent low back pain. J Pediatr Rehabil Med. 2018;11(2):79-94. https://doi.org/10.3233/ PRM-170526.

8. O'Sullivan K, O'Sullivan PB, O'Keeffe M, Forster BB, Qamar SR, van der Westhuizen A. Managing low back pain in active adolescents. Best Pract Res
Clin Rheumatol. 2019;33(1):102-21. https://doi.org/10.1016/j.berh.2019.02 005.

9. Moradi V, Memari A, ShayestehFar M, Kordi R. Low back pain in athletes is associated with general and sport specific risk factors: a comprehensive review of longitudinal studies. Rehabil Res Pract. 2015;2015:1-10. https://doi. org/10.1155/2015/850184.

10. Kibler WB, Press J, Sciascia A. The role of core stability in athletic function. Sports Med. 2006;36(3):189-98. https://doi.org/10.2165/00007256200636030-00001.

11. Roussel NA, Nijs J, Mottram S, Van Moorsel A, Truijen S, Stassijns G. Altered lumbopelvic movement control but not generalized joint hypermobility is associated with increased injury in dancers. A prospective study. Man Ther. 2009;14(6):630-5. https://doi.org/10.1016/j.math.2008.12.004.

12. Campbell A, O'Sullivan P, Straker L, Elliott B, Reid M. Back pain in tennis players: a link with lumbar serve kinematics and range of motion. Med Sci Sports Exerc. 2014;46(2):351. https://doi.org/10.1249/MSS.0b013e3182a45cca.

13. Ng L, Campbell A, Burnett A, Smith A, O'Sullivan P. Spinal kinematics of adolescent male rowers with back pain in comparison with matched controls during ergometer rowing. J Appl Biomech. 2015;31(6):459-68. https://doi.org/10.1123/jab.2015-0012.

14. Grosdent S, Demoulin C. Rodriguez de La Cruz, Carlos, Giop R, Tomasella M, Crielaard J, et al. Lumbopelvic motor control and low back pain in elite soccer players: a cross-sectional study. J Sci Med Sport. 2016;34(11):1021-9. https://doi.org/10.1080/02640414.2015.1085077.

15. Bayne H, Elliott B, Campbell A, Alderson J. Lumbar load in adolescent fast bowlers: a prospective injury study. J Sci Med Sport. 2016;19(2):117-22. https://doi.org/10.1016/j.jsams.2015.02.011.

16. Hernandez A, Gross K, Gombatto S. Differences in lumbar spine and lower extremity kinematics during a step down functional task in people with and people without low back pain. Clin Biomech (Bristol, Avon). 2017;47:46-52. https://doi.org/10.1016/j.clinbiomech.2017.05.012.

17. McClay IS, Robinson JR, Andriacchi TP, Frederick EC, Gross T, Martin P, et al. A profile of ground reaction forces in professional basketball. J Appl Biomech. 1994;10(3):222-36. https://doi.org/10.1123/jab.10.3.222.

18. Fuchs RK, Bauer JJ, Snow CM. Jumping improves hip and lumbar spine bone mass in prepubescent children: a randomized controlled trial. J Bone Miner Res. 2001;16(1):148-56. https://doi.org/10.1359/jbmr.2001.16.1.148.

19. Seay J, Selbie WS, Hamill J. In vivo lumbo-sacral forces and moments during constant speed running at different stride lengths. J Sci Med Sport. 2008; 26(14):1519. https://doi.org/10.1080/02640410802298235.

20. Pasanen K, Rossi MT, Parkkari J, Heinonen A, Steffen K, Myklebust G, et al. Predictors of lower extremity injuries in team sports (PROFITS-study): a study protocol. BMJ Open Sport Exerc Med. 2015;1(1):e000076. https://doi.org/10. 1136/bmjsem-2015-000076.

21. Kuorinka I, Jonsson B, Kilbom A, Vinterberg $H$, Biering-Sørensen $F$, Andersson G, et al. Standardised Nordic questionnaires for the analysis of musculoskeletal symptoms. Appl Ergon. 1987;18(3):233-7. https://doi.org/10. 1016/0003-6870(87)90010-X.

22. Bahr R, Andersen SO, Løken S, Fossan B, Hansen T, Holme I. Low back pain among endurance athletes with and without specific back loading-a cross-sectional survey of cross-country skiers, rowers, orienteerers, and nonathletic controls. Spine. 2004;29(4):449-54. https://doi.org/10.1097/01. BRS.0000096176.92881.37.

23. Takekawa KS, Gonçalves JS, Moriguchi CS, Coury H, de Oliveira Sato T. Can a self-administered questionnaire identify workers with chronic or recurring low back pain? Ind Health. 2015;53(4):340-5. https://doi.org/10.2486/ indhealth.2014-0241.

24. Leppänen M, Pasanen K. Kulmala J-, Kujala U, Krosshaug T, Kannus P, et al. knee control and jump-landing technique in young basketball and floorball players. Int J Sports Med. 2016;37(4):334-8. https://doi.org/10.1055/s-00351565104.

25. Leppänen M, Pasanen K, Kujala UM, Vasankari T, Kannus P, Äyrämö S, et al Stiff landings are associated with increased $A C L$ injury risk in young female basketball and floorball players. Am J Sports Med. 2017:45(2):386-93. https:// doi.org/10.1177/0363546516665810.

26. Stensrud S, Myklebust G, Kristianslund E, Bahr R, Krosshaug T. Correlation between two-dimensional video analysis and subjective assessment in evaluating knee control among elite female team handball players. $\mathrm{Br}\rfloor$ Sports Med. 2011;45(7):589-95. https://doi.org/10.1136/bjsm.2010.078287.

27. Nilstad A, Krosshaug T, Mok K, Bahr R, Andersen TE. Association between anatomical characteristics, knee laxity, muscle strength, and peak knee 
valgus during vertical drop-jump landings. JOSPT. 2015;45(12):998-1005. https://doi.org/10.2519/jospt.2015.5612.

28. Mok K, Petushek E, Krosshaug T. Reliability of knee biomechanics during a vertical drop jump in elite female athletes. Gait Posture. 2016;46:173-8. https://doi.org/10.1016/j.gaitpost.2016.03.003.

29. Krosshaug T, Steffen K, Kristianslund E, Nilstad A, Mok K, Myklebust G, et al. The vertical drop jump is a poor screening test for $A C L$ injuries in female elite soccer and handball players. Am J Sports Med. 2016;44(4):874-83. https://doi.org/10.1177/0363546515625048.

30. Ford K, Myer G, Smith R, Byrnes R, Dopirak S, Hewett T. Use of an overhead goal alters vertical jump performance and biomechanics. J Strength Cond Res. 2005;19(2):394-9. https://doi.org/10.1519/15834.1

31. Herrington L, Alenezi F, Alzhrani M, Alrayani H, Jones R. The reliability and criterion validity of $2 \mathrm{D}$ video assessment of single leg squat and hop landing Electromyogr Kinesiol 2017;34:80-85. doi: https://doi.org/10.1016/j. jelekin.2017.04.004.

32. Olsen O, Myklebust G, Engebretsen L, Bahr R. Injury mechanisms for anterior cruciate ligament injuries in team handball. Am J Sports Med. 2004;32(4): 1002-12. https://doi.org/10.1177/0363546503261724.

33. Fuller CW, Ekstrand J, Junge A, Andersen TE, Bahr R, Dvorak J, et al. Consensus statement on injury definitions and data collection procedures in studies of football (soccer) injuries. Scand J Med Sci Sports. 2006;16(2):8392.

34. R Core Team. R: A language and environment for statistical computing. Vienna; 2016.

35. Therneau TM. Coxme: mixed effects cox models. R package. 2015:2.2-5.

36. Peduzzi P, Concato J, Feinstein AR, Holford TR. Importance of events per independent variable in proportional hazards regression analysis II. Accuracy and precision of regression estimates. J Clin Epidemiol. 1995;48(12):1503-10. https://doi.org/10.1016/0895-4356(95)00048-8.

37. Peduzzi P, Concato J, Kemper E, Holford TR, Feinstein AR. A simulation study of the number of events per variable in logistic regression analysis. J Clin Epidemiol. 1996;49(12):1373-9. https://doi.org/10.1016/50895-4356(96)002363.

38. Karandikar N, Vargas OO. Kinetic chains: a review of the concept and its clinical applications. PM\&R. 2011;3(8):739-45. https://doi.org/10.1016/j.pmrj. 2011.02.021

39. Graci V, Salsich GB. Trunk and lower extremity segment kinematics and their relationship to pain following movement instruction during a single-leg squat in females with dynamic knee valgus and patellofemoral pain. J Sci Med Sport. 2014;18(3):343-7. https://doi.org/10.1016/j.jsams.2014.04.011.

40. Graham RB, Costigan PA, Sadler EM, Stevenson JM. Local dynamic stability of the lifting kinematic chain. Gait Posture. 2011;34(4):561-3. https://doi.org/ 10.1016/.gaitpost.2011.06.022.

41. Powers CM. The influence of abnormal hip mechanics on knee injury: a biomechanical perspective. JOSPT. 2010;40(2):42-51. https://doi.org/10.2519/ jospt.2010.3337.

42. Verrelst R, De Clercq D, Vanrenterghem J, Willems T, Palmans T, Witvrouw E. The role of proximal dynamic joint stability in the development of exertional medial tibial pain: a prospective study. Br J Sports Med. 2014; 48(5):388-93. https://doi.org/10.1136/bjsports-2012-092126.

43. Dingenen B, Malfait B, Nijs S, Peers KHE, Vereecken S, Verschueren SMP, et al. Can two-dimensional video analysis during single-leg drop vertical jumps help identify non-contact knee injury risk? A one-year prospective study. Clin Biomech (Bristol, Avon). 2015;30(8):781-7. https://doi.org/10.1016/ j.clinbiomech.2015.06.013.

44. Chaudhari AMW, McKenzie CS, Pan X, Oñate JA. Lumbopelvic control and days missed because of injury in professional baseball pitchers. Am J Sports Med. 2014;42(11):2734-40. https://doi.org/10.1177/0363546514545861.

45. Bayne H, Campbell A, Alderson J. Lumbar load in adolescent fast bowlers: a prospective injury study. J Sci Med Sport. 2015;19(2):117-22. https://doi.org/ 10.1016/j.jsams.2015.02.011.

46. Dingenen B, Malfait B, Vanrenterghem J, Verschueren SMP, Staes FF. The reliability and validity of the measurement of lateral trunk motion in twodimensional video analysis during unipodal functional screening tests in elite female athletes. Phys Ther Sport. 2013;15(2):117-23. https://doi.org/10. 1016/j.ptsp.2013.05.001

47. Kankaanpää M, Taimela S, Laaksonen D, Hänninen O, Airaksinen O. Back and hip extensor fatigability in chronic low back pain patients and controls. Arch Phys Med Rehabil. 1998;79(4):412-7. https://doi.org/10.1016/S00039993(98)90142-3.
48. Müller S, Stoll J, Müller J, Cassel M, Mayer F. Trunk muscle activity during drop jump performance in adolescent athletes with back pain. Front Physiol. 2017;8. https://doi.org/10.3389/fphys.2017.00274.

49. van der Worp H, Vrielink JW, Bredeweg SW. Do runners who suffer injuries have higher vertical ground reaction forces than those who remain injuryfree? A systematic review and meta-analysis. Br J Sports Med. 2016;50(8):659. https://doi.org/10.1136/bjsports-2015-094924.

50. Smith AJ, O'Sullivan PB, Beales D, Straker L. Back pain beliefs are related to the impact of low back pain in 17-year-olds. Phys Ther. 2012;92(10):1258-67. https://doi.org/10.2522/ptj.20110396.

51. Watson A, Brickson S, Brooks A, Dunn W. Subjective well-being and training load predict in-season injury and illness risk in female youth soccer players. Br J Sports Med. 2017;51(3):194. https://doi.org/10.1136/bjsports-2016096584.

52. Linek $P$, Noormohammadpour $P$, Mansournia MA, Wolny T, Sikora D. Morphological changes of the lateral abdominal muscles in adolescent soccer players with low back pain: a prospective cohort study. I Sport Health Sci. 2018. https://doi.org/10.1016/j.jshs.2018.02.002.

53. Meeuwisse W, Tyreman H, Hagel B, Emery C. A dynamic model of etiology in sport injury: the recursive nature of risk and causation. Clin J Sport Med. 2007;17(3):215-9. https://doi.org/10.1097/JSM.0b013e3180592a48.

\section{Publisher's Note}

Springer Nature remains neutral with regard to jurisdictional claims in published maps and institutional affiliations.
Ready to submit your research? Choose BMC and benefit from:

- fast, convenient online submission

- thorough peer review by experienced researchers in your field

- rapid publication on acceptance

- support for research data, including large and complex data types

- gold Open Access which fosters wider collaboration and increased citations

- maximum visibility for your research: over $100 \mathrm{M}$ website views per year

At BMC, research is always in progress.

Learn more biomedcentral.com/submissions 